\title{
CHARACTERISTICS AND RESULTS OF THE NEAR REAL-TIME SYSTEM FOR ESTIMATING THE SEISMIC DAMAGE IN ROMANIA
}

\author{
TOMA-DANILA DRAGOS - Researcher, National Institute for Earth Physics, Romania, e-mail: toma@infp.ro \\ CIOFLAN CARMEN ORTANZA - Senior Researcher, National Institute for Earth Physics, Romania \\ BALAN STEFAN FLORIN - Senior Researcher, National Institute for Earth Physics, Romania \\ MANEA ELENA FLORINELA - Research assistant, National Institute for Earth Physics, Romania
}

\begin{abstract}
The Near Real-Time System for Estimating the Seismic Damage in Romania, implemented in 2012 at the National Institute for Earth Physics, is one of the automated systems that can directly contribute to saving many lives right after a major earthquake, by translating earthquake parameters into damage probabilities for different areas within Romanian counties and showing emergency intervention necessities, and can also lead to mitigation actions before an earthquake, through raising awareness and highlighting vulnerable aspects of the building stock and economic and social impacts.

This paper aims to present the scientific background of this constantly upgrading system, and to show different results for relevant scenarios, for intermediate-depth Vrancea earthquakes and other crustal earthquakes. Several important questions are tried to be answered, like: "How credible are the estimated losses?", "What are the most vulnerable aspects?" or "How can the damage maps be useful for authorities?".

Currently, the system uses for building loss estimation the analytical methods (as the ImprovedDisplacement Capacity Method - I-DCM) implemented within the open-source software SELENA (SEismic Loss EstimatioN using a logic tree Approach), together with HAZUS methods for estimating the human casualties. The building stock is defined through 48 different capacity and fragility curves, depending on construction material, height and age. As hazard data, PGA and SA values obtained through the ShakeMap System and based on real recordings and attenuation relations are used. The area currently analyzed by the system consists of 19 Romanian Counties, capital Bucharest and 9 regions in northern Bulgaria; resolution of the data is at administrative unit (commune or city) level. We aim to provide an insight of each part of this system, justify the choices made and also discuss the improvement possibilities.
\end{abstract}

Keywords: loss assessment, seismic risk, SELENA

\section{Introduction}

Over past decades, in order to assist decision-makers, planners and structural engineers in assessing the seismic risk on buildings and infrastructure, Earthquake Loss Estimation Software (ELES) tools were developed, based on various approaches (analytical, empirical, hybrid). The use of GIS (Geographic Information Systems) and the ad of social and economic loss assessment modules greatly improved the impact on stake-holders.

The research has been pioneered by projects in the US and Japan (starting in '70), with notable impact of the development of HAZUS multi-hazard software (CFEMA, US). In Europe, due to the lack of a coordinator institution at above-state level, many ELES emerged from the HAZUS core and tried to adapt it to each country's specific. Within recent projects like RISK-UE, SAFER, LESSLOSS or NERIES, the state-of-the-art was studied and new generally applicable risk tools were created (some of them open-source), based on new risk assessment methods (improvements of the Capacity Spectrum Methodology in HAZUS, pushover and displacementbased methods). In table 1, a descriptive list of the most important ELES nowadays is showed. 
Newer ELES can be used within near real-time loss estimation systems, by using directly values of acceleration as input, together with vulnerability data. At European level, seismic prone countries like Turkey, Italy and Romania tested with proper results this types of systems, in order to validate the quality of the estimations. National authorities are interested in risk analysis and maps - as an applicative result of research, but the degree of error that ELES software will always have to be dealt accordingly.

Table 1

State-of-the art ELES (D-district, Ci-city, DP-deterministic predicted, DO-deterministic observed, P-probabilistic)

\begin{tabular}{|l|l|l|l|l|l|}
\hline ELES & Modifiable & Region & Exposure & Hazard & Vulnerability \\
\hline DBELA & Yes & World & $\mathrm{D}, \mathrm{Ci}$ & $\mathrm{DP}, \mathrm{DO}, \mathrm{P}$ & Analytical \\
\hline ELER & Yes & Europe & $\mathrm{D}, \mathrm{Ci}$ & $\mathrm{DP}, \mathrm{DO}, \mathrm{P}$ & Both \\
\hline EQSIM & Yes & Europe & $\mathrm{D}, \mathrm{Ci}$ & $\mathrm{DP}, \mathrm{DO}$ & Analytical \\
\hline HAZUS-MH & & North-America & Multi & $\mathrm{DP}, \mathrm{DO}, \mathrm{P}$ & Analytical \\
\hline OPENRISK & Yes & World & $\mathrm{Multi}$ & $\mathrm{DP}, \mathrm{DO}, \mathrm{P}$ & Empirical \\
\hline SAFER & & World & $\mathrm{D}, \mathrm{Ci}$ & $\mathrm{DP}, \mathrm{DO}, \mathrm{P}$ & Both \\
\hline SELENA & Yes & World & $\mathrm{D}, \mathrm{Ci}$ & $\mathrm{DP}, \mathrm{DO}, \mathrm{P}$ & Analytical \\
\hline
\end{tabular}

In Romania it is much needed an estimation of the potential losses, since it is clear that a major earthquake will occur and cause effects on a significant extent, in short time. The seismicity is characterized mainly by the Vrancea intermediate depth source, which statistically produces 2-3 events per century with magnitude greater than 7 . There are also other crustal areas that can have a strong impact locally. All these can be depicted from figure 1.

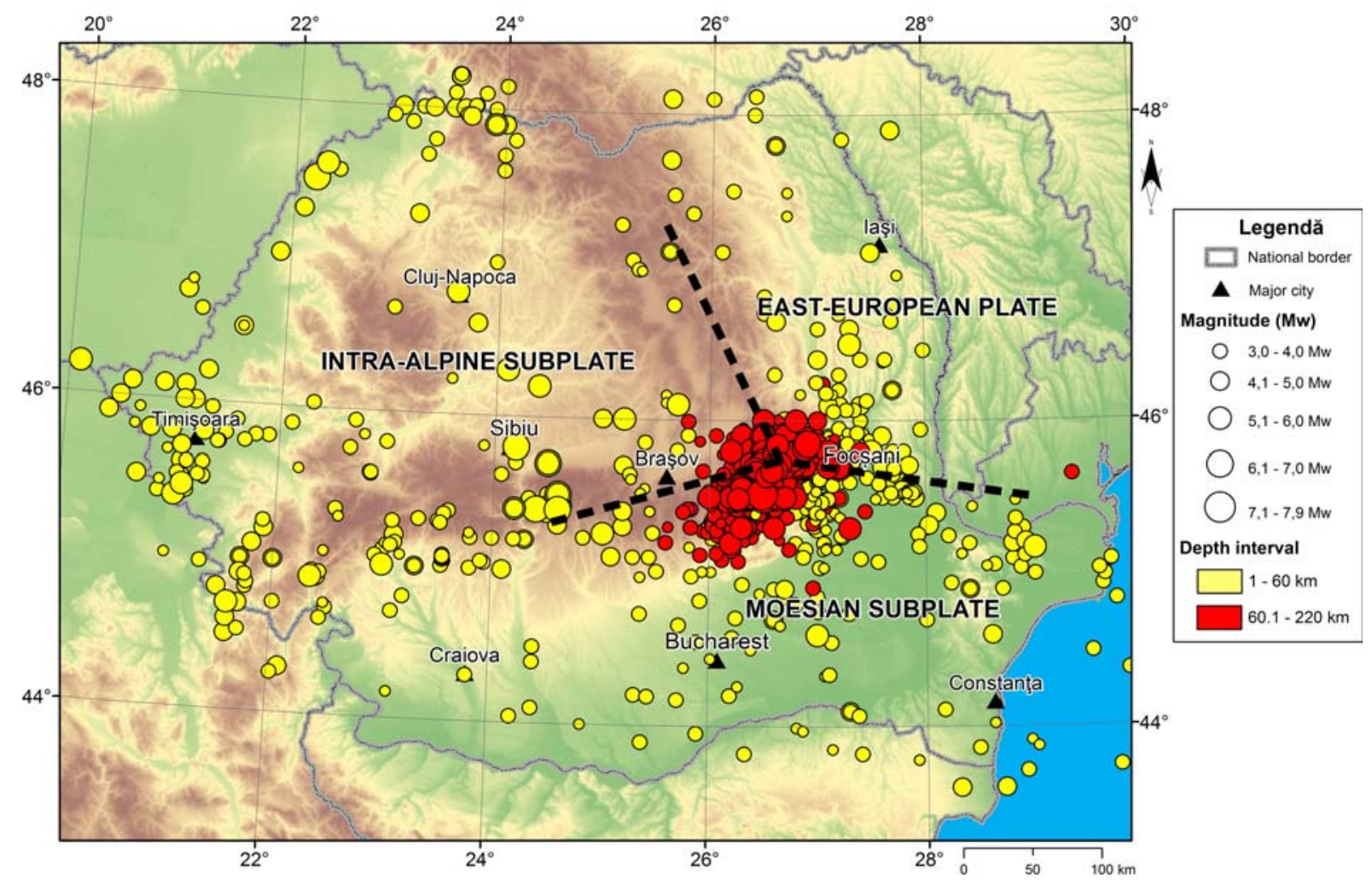

Fig. 1 - Map of the earthquake epicenters from the ROMPLUS Catalogue (Jan 2014 edition) [1], for events with moment magnitude $\geq 3$

Up to now, some of the efforts of analyzing the possible losses in Romania included:

- The individual evaluation of buildings: starting from 1993, 373 old buildings in Bucharest (out of 2563) evaluated by experts [2] and 294 in 19 other cities were included in the $1^{\text {st }}$ seismic risk class [3]. Only 38 buildings were consolidated. But the total 
number of residential buildings was 113900 (in 2011) in Bucharest and more than 4.8 million (in 2010) at country level [4].

- Within the SHARE Project, an experimental study [5] was conducted in order to assess the seismic losses for Bucharest. It used SELENA, and building typologies defined according to main structural material (7 types), height (3 types) and level of code design (before and after 1977). Four different ground motion predicting equations (GMPE) were used, and the results consisted in an overview of the damaged buildings, economic losses and people affected, at city level.

Due to the complexity of obtaining veridical results, very few studies have been published. Through this paper we present a system meant to fill the gap and make use a newly compiled vulnerability database together with real recorded data and past events.

The objectives of this study are:

- To present the characteristics and the current state of the Near Real-Time System for Estimating the Seismic Damage in Romania, operated by the National Institute for Earth Physics (NIEP)

- To present relevant results of this system, proving it's functionality and utility

- To highlight the future improvements needed to be taken into consideration

\section{System characteristics}

The Near Real-Time System for Estimating the Seismic Damage in Romania started functioning from 2011, and it is under continuous upgrading. The flowchart of the current system can be seen in figure 1. Right after an earthquake occurs on or near the Romanian territory (in the Vrancea subcrustal area or in crustal areas like Banat, Shabla, Fagaras-Campulung, Black-Sea), an automatic evaluation of the basic parameters (like epicenter location, depth and magnitude) is performed by the Antelope software, based on the digital recordings of more than 150 seismic stations. If the magnitude is $\geq 4 \mathrm{M}_{\mathrm{L}}$, ground motion parameters from each station together with the seismic bulletin are sent to the ShakeMap software; this transfers the data and bias it (if needed) with specific GMPE in order to generate a grid of points covering the entire country, with information about the peak ground acceleration (PGA) and spectral acceleration (SA).

The ShakeMap output is later used by the software for estimating the losses at city/commune level: SELENA. This is an open-source software developed by the NORSAR Institute and adapted to the Romanian-Bulgarian specific within the DACEA Project (DAnube Cross-border system for Earthquake Alert). Its purpose is to link the seismic behavior previously defined at local site and at surface to the comportment of building structures that are defined in the associated vulnerability database, obtaining probabilities for damage states and later probabilities for socio-economic damage. It is based on the analytical approach described in Subchapter 2.1. With the current vulnerability database used by SELENA, the processing time is 5 minutes for 1483 calculation points (geounits), including calculations, maps, tables and GIS data generation and forwarding to external applications or email lists. Since its first implementation for the Danube crossborder region, the area analyzed was extended, covering today 19 Romanian Counties, the 6 sector of the Bucharest Capital and 9 Bulgarian northern provinces.

Another relatively similar software used in parallel is THIMA - which was developed within the DACEA Project by the Technical University of Civil Engineering Bucharest (UTCB). The specific task of THIMA is to estimate the potential seismic failure of important buildings (like schools, hospitals, city halls or emergency unit centers) in the project Area. Computing time is 2 minutes, for 722 buildings. Due to the fact that it is hardcoded and intimately addressed to the DACEA Project, it will not make the subject of this article. 


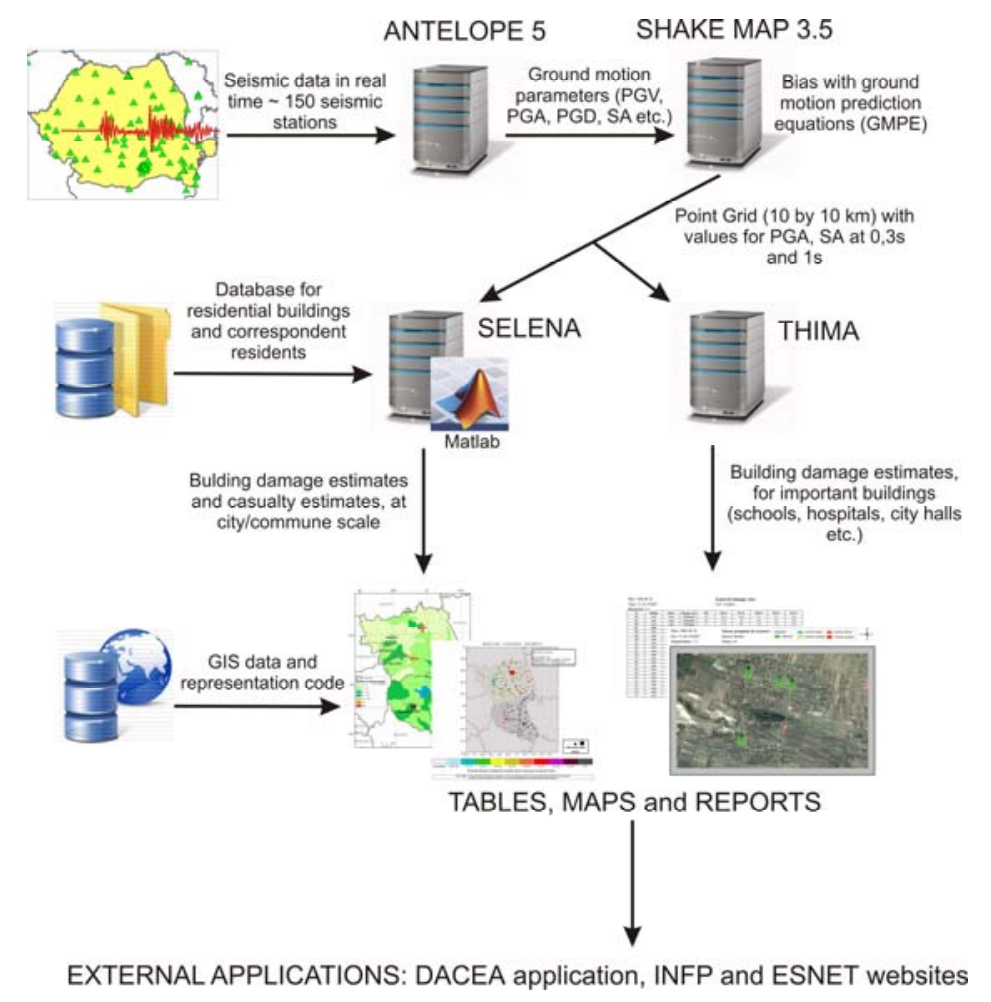

Fig. 2 - Flowchart of the Near Real-Time System for Estimating the Seismic Damage

\subsection{Methodology for computing loss estimates}

Analytical methods used by SELENA and THIMA are based on the idea that any building (generally modeled as a single degree of freedom system - SDOF) is structurally damaged by the spectral displacement and not by the spectral acceleration itself. For each building, the inter-story drift is a function of the applied lateral force that can be analytically determined and transformed into building capacity curves, based on yield or ultimate points [6].

In SELENA, the I-DCM method was preferred because it provided a good fit in simulations with the actual damage reported in real earthquakes and because it is one the recommended methods of SELENA, due to the algorithm that allows fast computation time and to the scientific base. Differently from other capacity spectrum methods (like CSM or MADRS), I-DCM modifies the displacement demand of the equivalent SDOF by multiplying it by a series of coefficients in order to generate an estimate of the maximum displacement demand of the nonlinear oscillator [7]. In THIMA, the more classic approach of the CSM method was preferred.

In order to express the probability distributions of the damage, fragility functions (curves) are developed, based on observed behavior of the structures in real situations or after computerbased analysis (like numerically simulated seismic response). Usually, the damage is characterized by specific damage states, like no damage, slight, moderate, extensive and complete (as in [8]). For each building typology, a specific damage probability is obtained by plotting on the fragility functions the spectral displacement coordinates of the target displacement point $\left(\delta_{t}\right)$.

The specific hazard input (in terms of PGA and SA at different periods) is used in generating an elastic response spectrum, which can be obtained through different methods, like Eurocode 8 and IBC2006. In order to use this spectrum with I-DCM, it is needed to convert it into ADRS format, through the following formula:

$$
S_{d e}=\left(\frac{T^{2}}{4 \pi^{2}}\right) S_{a e}
$$



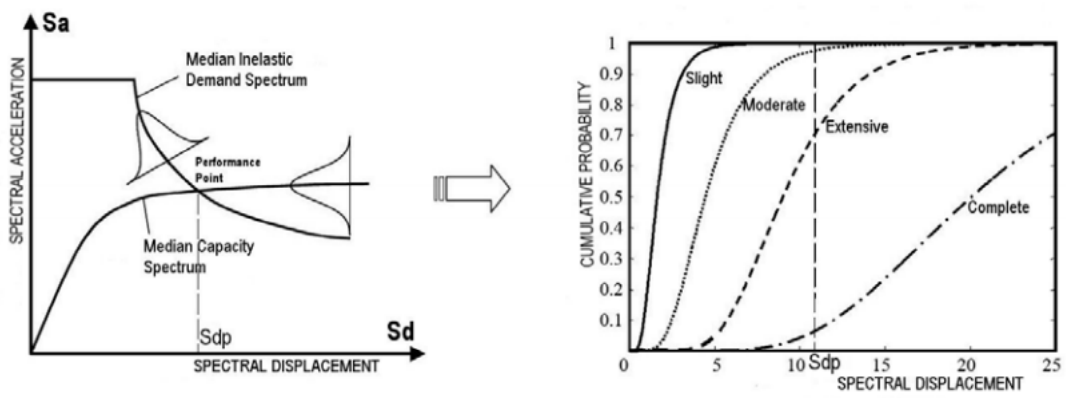

Fig. 3 - Illustration of the methodology for computing damage state probabilities for a certain building typology; the left graph shows how the performance point is derived and the right graph shows how probabilities are found, using fragility curves [8]

The socio-economic damage estimates are calculated using empirical models, based also on the results of the building analysis. For the human casualties $\left(\mathrm{K}_{\mathrm{ij}}\right)$, the empirical calculated casualty rates (derived from real earthquakes assessment) are used. The formula used also in the system presented is presented below (2).

$$
\begin{aligned}
K_{i j}= & \text { Population per Building * Number of Damaged Building in damage state } j^{*} \text { Casualty } \\
& \text { Rate for severity level } i \text { and damage state } j
\end{aligned}
$$

\subsection{Hazard data}

As mentioned before, for the description of the ground motion parameters we use real-time data from the seismic stations of the National Seismic Network managed by NIEP. Most of them have a good noise-signal report, are free field and they're instrumentation consist generally both on velocity (broadband or short period) and strong motion sensors.

Due to the inter-event variability effect [9], a bias between the data values at the seismic stations and the estimated values at these locations is computed by ShakeMap. This require a GMPE; for the Vrancea intermediate-depth seismic source, a specific GMPE developed by Sokolov et al. (2008) [10] is used. This equation is described in a GEM report [11] as the only one that "passes the selection criteria of Cotton et al. for areas of deep focus non-subduction earthquakes", and it is in the form:

$$
\ln (\mathrm{PGA} \text { or } \mathrm{SA})=\mathrm{a} 1+\mathrm{a} 2 * \ln \mathrm{Mw}-(\exp (\mathrm{a} 3+\mathrm{a} 4 * \ln \mathrm{H})) * \mathrm{R}+\mathrm{a} 5 * \mathrm{H}
$$

in which PGA or SA is in $\mathrm{cm} / \mathrm{s}^{2}, \mathrm{Mw}$ is moment magnitude, $\mathrm{H}$ is the depth (in $\mathrm{km}$ ), $\mathrm{R}$ is the epicentral distance (in $\mathrm{km}$ ) and the a coefficients are region dependent.

For crustal earthquakes, the GMPE used is Boore et al. (1997) [9].

The system can also be used with scenarios, by either providing an input similar to the ShakeMap grid or by following the specifications of the SELENA hazard modules. The Sokolov GMPE is not yet implemented in SELENA for a deterministic scenario, however the Marmureanu et al. (2006) [5] equation can be used for Vrancea earthquakes as an alternative. Also, when spectral acceleration values are not available, the spectrum can be calculated through Eurocode8 default parameters for SA at $0.3 \mathrm{~s}$ and $1 \mathrm{~s}$.

\subsection{Vulnerability data}

The task of obtaining a detailed enough vulnerability database corresponding to the specific needs was hard, but it was accomplished through the DACEA Project, by NIEP, UTCB (Technical University of Constructions Bucharest) and NORSAR Institute. A complex database with information about buildings and their residents dating 1999, at city/commune level was used for 
SELENA. Giving that not a lot have changed and new buildings are expected to perform much better than older buildings, the data can be considered also fit for present. As seen in figure 4, this database covers 19 Romanian counties and Bucharest capital, and 9 Bulgarian northern provinces.

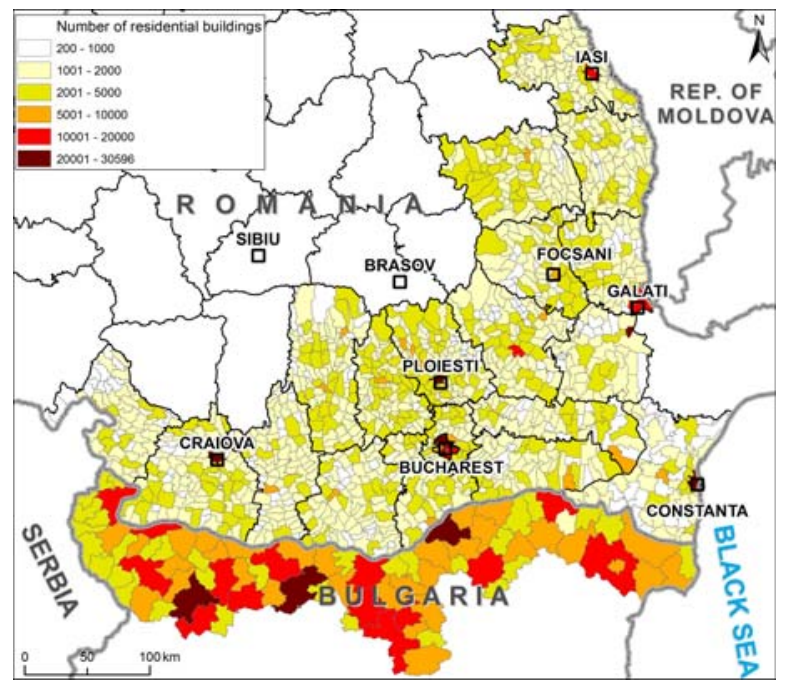

Fig. 4 - Map showing the extent of the SELENA building and population database and the total number of residential buildings

In order to associate capacity and fragility curves to the specific buildings by SELENA, buildings in the database were classified according to building material, height and construction year. These parameters determined a specific vulnerability curve correspondent, as defined in Table 2. As it can be seen, some curves are borrowed from universal literature and not calculated for buildings constructed according to local practices and seismic design codes, so the uncertainties are not to be neglected. Also, in the SELENA analysis, the vulnerability curves have to account for multiple types of buildings, providing somehow a mean for an entire class.

Table 2

Structure of the buildings database compiled in DACEA Project for SELENA, with 48 associated vulnerability curves (from [12])

\begin{tabular}{|c|c|c|c|c|c|c|c|}
\hline & \multicolumn{2}{|c|}{ Construction material } & $\begin{array}{l}\text { Mate } \\
\text { rial } \\
\text { Code }\end{array}$ & $\begin{array}{l}\text { Height } \\
\text { class }\end{array}$ & $\begin{array}{l}\text { Construction } \\
\text { code }\end{array}$ & \multicolumn{2}{|c|}{$\begin{array}{l}\text { Vulnerability curves } \\
\text { Sources: }{ }^{1}[8],{ }^{2}[13]\end{array}$} \\
\hline 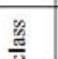 & \multicolumn{2}{|l|}{ Adobe } & M2 & $\mathrm{L}$ & $\begin{array}{l}\mathrm{PC}, \mathrm{LC}, \mathrm{MC}, \\
\mathrm{HC}\end{array}$ & \multicolumn{2}{|c|}{ URM-L-PC ${ }^{1}$} \\
\hline$\frac{\square}{g}$ & \multicolumn{2}{|c|}{$\begin{array}{l}\text { Unreinforced masonry bearing } \\
\text { walls with flexible floors }\end{array}$} & M3_1 & $\mathrm{L}$ & PC, LC, MC & \multicolumn{2}{|c|}{ URM-L-PC ${ }^{1}$} \\
\hline$\frac{3}{\frac{3}{5}}$ & \multicolumn{2}{|c|}{$\begin{array}{l}\text { Unreinforced masonry bearing } \\
\text { walls with flexible floors }\end{array}$} & M3_1 & $\mathrm{M}, \mathrm{H}$ & $\mathrm{PC}, \mathrm{LC}, \mathrm{MC}$ & \multicolumn{2}{|c|}{ URM-M-PC 1} \\
\hline$\frac{\stackrel{0}{0}}{\frac{0}{2}}$ & \multicolumn{2}{|c|}{$\begin{array}{l}\text { Unreinforced masonry bearing } \\
\text { walls with rigid floors }\end{array}$} & M3_2 & $\mathrm{L}$ & $\mathrm{PC}, \mathrm{LC}, \mathrm{MC}$ & \multicolumn{2}{|c|}{ URM-L-LC ${ }^{1}$} \\
\hline $\bar{\varepsilon}$ & \multicolumn{2}{|c|}{$\begin{array}{l}\text { Unreinforced masonry bearing } \\
\text { walls with rigid floors }\end{array}$} & M3_2 & $\mathrm{M}, \mathrm{H}$ & $\mathrm{PC}, \mathrm{LC}, \mathrm{MC}$ & \multicolumn{2}{|c|}{ URM-M-LC' } \\
\hline 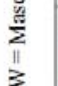 & \multicolumn{2}{|c|}{$\begin{array}{l}\text { Reinforced or confined masonry } \\
\text { bearing walls or retrofitted (overall } \\
\text { strengthened) masonry buildings }\end{array}$} & M4 & $\begin{array}{l}\text { L, M, } \\
\text { H }\end{array}$ & $\mathrm{HC}$ & \multicolumn{2}{|c|}{$\mathrm{M} 7-2, \mathrm{M} 7-4, \mathrm{M} 7-6^{2}$} \\
\hline$\sum$ & \multicolumn{2}{|c|}{ Wood structures } & W & $\mathrm{L}$ & $\begin{array}{l}\mathrm{PC}, \mathrm{LC}, \mathrm{MC}, \\
\mathrm{HC}\end{array}$ & \multicolumn{2}{|c|}{ W1-PC(LC, MC, HC $)^{1}$} \\
\hline 总 & \multicolumn{2}{|c|}{ Concrete shear walls } & $\mathrm{RC2}$ & $\begin{array}{l}\text { L, M, } \\
\text { H }\end{array}$ & $\begin{array}{l}\text { PC, LC, MC, } \\
\text { HC }\end{array}$ & \multicolumn{2}{|c|}{$\begin{array}{l}\mathrm{C} 2-\mathrm{L}(\mathrm{M}, \mathrm{H})-\mathrm{PC}(\mathrm{LC}, \mathrm{MC}, \mathrm{HC}) \\
\text { fragility curve }+ \text { modified } \\
\text { capacity curve (by UTCB) }\end{array}$} \\
\hline 昙 & \multicolumn{2}{|c|}{$\begin{array}{l}\text { Concrete frame with unreinforced } \\
\text { masonry infill walls }\end{array}$} & $\mathrm{RC} 3$ & $\begin{array}{l}\mathrm{L}, \mathrm{M}, \\
\mathrm{H}\end{array}$ & $\begin{array}{l}\mathrm{PC}, \mathrm{LC}, \mathrm{MC}, \\
\mathrm{HC}\end{array}$ & \multicolumn{2}{|c|}{$\begin{array}{l}\text { C3-L(M,H)-PC(LC,MC,HC) } \\
\text { fragility curve } 1+\text { modified } \\
\text { capacity curve (by UTCB) }\end{array}$} \\
\hline$\ddot{\sim}$ & \multicolumn{2}{|c|}{ Precast concrete walls } & RC5 & $\begin{array}{l}\mathrm{L}, \mathrm{M}, \\
\mathrm{H}\end{array}$ & $\begin{array}{l}\mathrm{PC}, \mathrm{LC}, \mathrm{MC}, \\
\mathrm{HC}\end{array}$ & \multicolumn{2}{|c|}{$\mathrm{PC} 2-\mathrm{L}(\mathrm{M}, \mathrm{H})-\mathrm{PC}(\mathrm{LC}, \mathrm{MC}, \mathrm{HC})^{1}$} \\
\hline \multicolumn{8}{|c|}{ Legend: } \\
\hline \multirow{3}{*}{\multicolumn{2}{|c|}{$\begin{array}{l}\text { Height Class } \\
\text { abbreviations: } \\
\text { Construction Code } \\
\text { abbreviations: }\end{array}$}} & \multicolumn{3}{|c|}{$\mathrm{L}=\mathrm{Low}-\max 2$ storeys } & \multicolumn{2}{|c|}{$\mathrm{M}=\mathrm{Medium}-3-5$ storeys } & $\begin{array}{l}\mathrm{H}=\mathrm{High}-\min 6 \\
\text { storeys }\end{array}$ \\
\hline & & \multicolumn{3}{|c|}{$\mathrm{PC}=$ PreCode - older than 1963} & \multicolumn{2}{|c|}{ LC $=$ LowCode $-1963-1977$} & \\
\hline & & \multicolumn{3}{|c|}{$\begin{array}{l}\text { MC }=\text { Moderate Code }-1978- \\
1991\end{array}$} & \multicolumn{2}{|c|}{$\begin{array}{l}\mathrm{HC}=\text { High Code }-1991- \\
1999\end{array}$} & \\
\hline
\end{tabular}




\subsection{GIS Module for map representations}

Custom GIS modules were developed both for SELENA and THIMA, in order to create the means for properly disseminating the results. Since the output results have a spatial component that needs to be highlighted, maps are the best representations for the loss estimates. For these maps it was also taken into consideration that in order to be useful right after a major earthquake, they have to be easy to read. That is why, although each software offers detailed reports for each typology of buildings, we considered better to show a Mean Damage Ratio (MDR) as parameter, for SELENA. This is calculated by dividing the number of buildings with complete damage probability to the total number of buildings in the geounit.

These modules converts data into specific GIS formats (.shp, .kml, .geojson), produce ready to use and print maps with the MDR or the estimated state of important buildings and with estimated number of people severely injured, and send the data to webgis applications or email lists.

\section{Results}

In order to show actual results of the real-time system, we present maps obtained automatically, for simulated major earthquakes - since there wasn't yet a recent earthquake large enough to produce damage estimates or real damage (since 2011).

Multiple tests have been performed for system evaluation, and the conclusions showed that:

- Compared with real damage recorded in major earthquakes (like the ones in 1977, 1986 or 1990), the system's results are slightly overestimated (still less than twice in general, as for the human casualty estimation for the 1977 earthquake), still this is a good thing society is even more vulnerable today, damage estimates will never match entirely reality and for mitigation purposes - a worst case scenario is more useful.

- For Vrancea Area smaller magnitude earthquakes (less than 6), there is no damage calculated by the system, which is correspondent to the actual situation expected and experienced several times before (considering direct damage)

- The time it takes to compute is sufficient - finished maps can be visualized in maximum 10 minutes after the earthquake.

- Final beneficiaries showed great interest in the results and their representation form, since they can interpret much quicker the results, not requiring expert knowledge

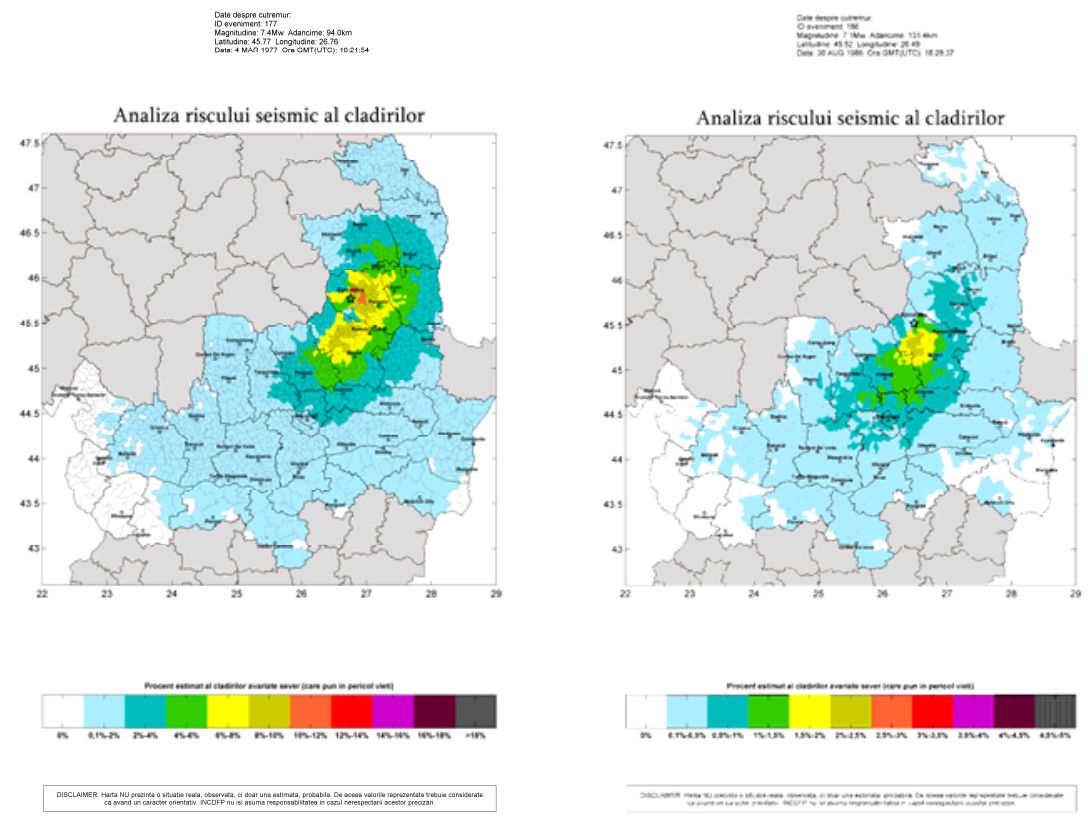

Fig. 5 - Results from SELENA, for a simulation of the 1977 Vrancea earthquake (Mw 7.4, H $94 \mathrm{~km}$ ) - left, and of the 1986 Vrancea earthquake (Mw 7.1, H $131 \mathrm{~km}$ ) - right, showing the MDR for buildings (translated into "percentage of buildings that can present life-threatening damage") 


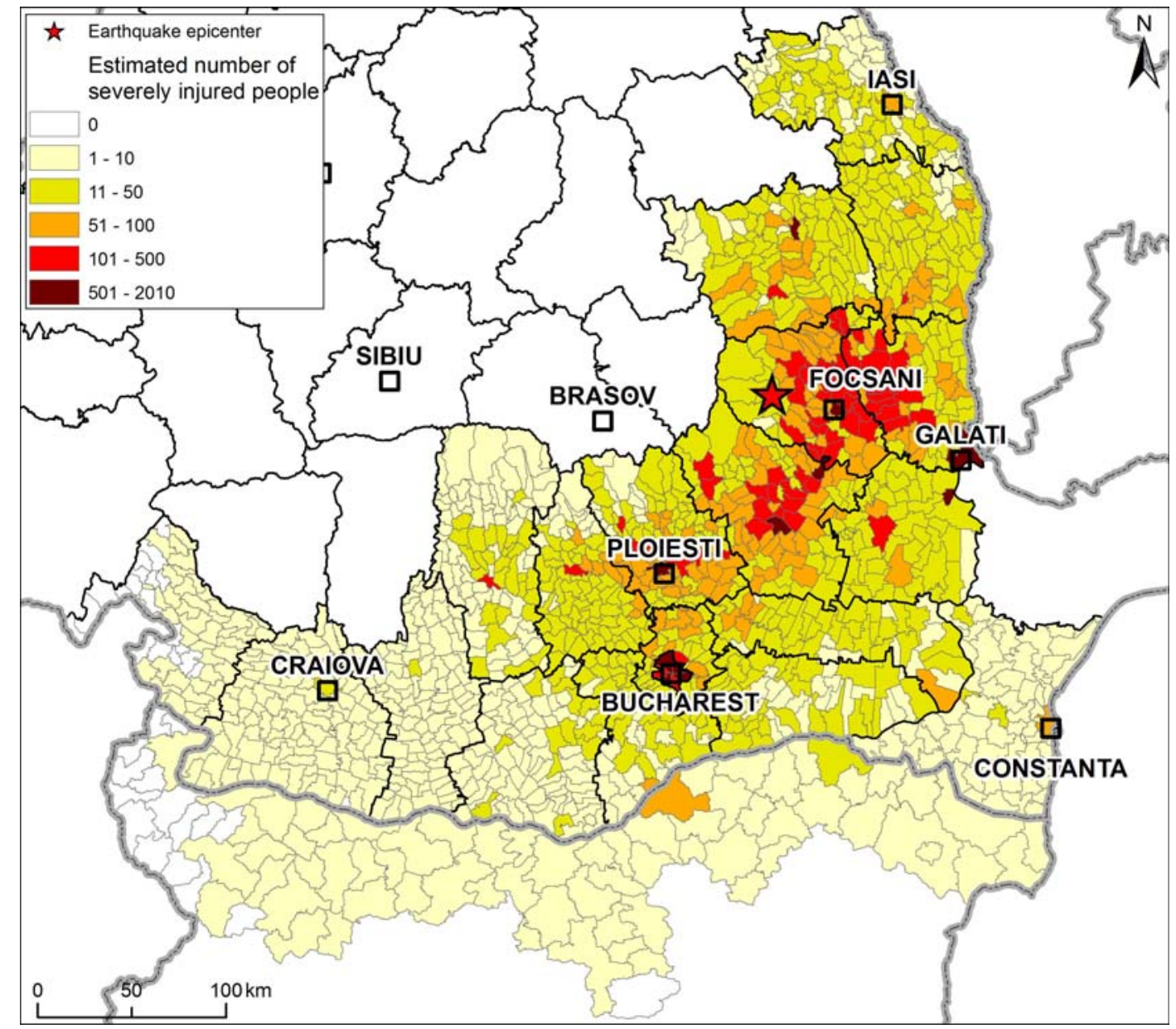

Fig. 6 - Results from SELENA, for a simulation of the 1977 Vrancea earthquake (Mw 7.4, H 94 km), showing the estimated number of severely injured people (severity grades $3+4$ )

\section{Conclusions}

This paper presented the actual status of the Near Real-Time System for Estimating the Seismic Damage operated by NIEP, with detailed insight into its framework and database characteristics. Also some of the results were presented, proving the functionality of the system and the proper fit of the estimates within the credible ranges for damage; these can be also seen in greater detail in focused regional studies like [14].

Through this study we showed that in the last years progress was made in the loss estimation of the seismic damage, creating possibilities for better mitigation or emergency plans, short and long term strategies and quick intervention on a large scale. Although other attempts were tried before, this is currently the only functional real-time system in Romania, benefitting from a complex database for buildings and population.

Future development is a continuous task; the actions taken into consideration are currently:

- Updating and upgrading the static database with data from the 2011 census: a better resolution of the data, especially in urban area, is to be obtained, and all counties of Romania must be included.

- Determining regionally adapted vulnerability curves, through computer based modeling

- Use of more detailed spectra (following the P100 national code regulations) for the hazard definition (with more spectral acceleration periods, especially in the 1-2 seconds interval) 
- Development and implementation of newer GMPE's, especially for crustal areas

- Improving the overall computational time of the system

\section{Acknowledgements}

The contribution of the Danube Cross-border system for Earthquakes Alert (DACEA) Project (Contract Number: 52570/05.08.2010) is greatly appreciated. Also authors would like to mention the financial support provided through doctoral scholarships. The paper was presented in the $5^{\text {th }}$ National Conference of Earthquake Engineering and The $1^{\text {st }}$ National Conference on Earthquake Engineering and Seismology (19-20 June 2014).

\section{References}

[1] National Institute for Earth Physics (January 2014). Romplus Earthquake Catalogue.

[2] Bucharest Local Administration (May 2014). List of expertised buildings. Retrieved May 2014, from http://www.pmb.ro/servicii/alte_informatii/lista_imobilelor_exp/docs/Lista_imobilelor_expertizate.pdf

[3] Gandul Newspaper (November 2013). The map of buildings that can collapse in an earthquake similar to the one in 1977. Retrieved May 2014, from http://storage0.dms.mpinteractiv.ro/media/1/186/3927/11538171/3/risc-seismic.png

[4] Lungu C. (2012). Evaluarea fondului de cladiri din Romania in perspectiva aplicarii directivei 2010/CE/31; Conferinta Internationala despre Constructii Sustenabile si Eficienta Energetica. Retrieved May 2014 from http://www.euroconferinte.ro/prezentari/Tema1-17.pdf

[5] Lang D., Molina-Palacios S., Lindholm C., Balan S.F. (2012). Deterministic earthquake damage and loss assessment for the city of Bucharest, Romania. Journal of Seismology, 16, 67-88. DOI: 10.1007/s10950-0119250-y

[6] Erduran E., Toma-Danila D., Aldea A. et al. (2012). Real Time Earthquake Damage Assessment in RomanianBulgarian Border. 15 World Conference on Earthquake Engineering, Lisbon, Portugal

[7] Molina, S., Lang, D.H., Lindholm, C.D., Lingvall, F. (2010). SEismic Loss EstimatioN using a logic tree Approach (SELENA) [computer software]. Norway: NORSAR.

[8] Federal Emergency Management Agency (FEMA) (2004). Multi-hazard Loss Estimation Methodology, Earthquake Model, Advanced Engineering Building Module (HAZUS-MH) [computer software]. Washington DC: FEMA

[9] Boore, D. M., W. B. Joyner, and T.E. Fumal (1997). Equations for Estimating Horizontal Response Spectra and Peak Accelerations from Western North American Earthquakes: A Summary of Recent Work, Seism. Res. Lett., 68,128-153.

[10] Sokolov, V., Bonjer, K.P., Wenzel, F. (2004). Accounting for site effect in probabilistic assessment of seismic hazard for Romania and Bucharest: a case of deep seismicity in Vrancea zone. Soil Dynamics and Earthquake Engineering, 24, 929-947. DOI: 10.1016/j.soildyn.2004.06.021

[11] Douglas, J., Cotton, F., Abrahamson, N., Akkar, S., Boore, D.M., Di Alessandro. C. (2011). Pre-selection of ground-motion prediction equations. Global GMPEs Project, deliverable: Task 2

[12] Toma-Danila D., Zulfikar C., Manea E.F., Cioflan C.O. (2015) - Improved seismic risk estimation for Bucharest, based on multiple hazard scenarios and analytical methods; Soil Dynamics and Earthquake Engineering, accepted for publishing.

[13] Cattari S., Curti E., Giovinazzi S., Lagomarsino S., Parodi S., Penna A. (2004) - Un modello meccanico per l'analisi di vulnerabilita del costruito in muratura a scala urbana. 11th Conference "L'ingegneria Sismica in Italia", Genova, Italy.

[14] Toma-Danila D. (2012) - Real-Time Earthquake damage assessment and GIS analysis of two vulnerable counties in the Vrancea Seismic Area, Romania; Environmental Engineering and Management Journal, 11 (12), 2265-2274. WOS:000314169000018 